\title{
Successful Treatment of Two Cases of Squamous Cell Carcinoma on the Ear with Intra-Arterial Administration of Peplomycin through a Superficial Temporal Artery
}

\author{
Takahiro Haga $^{a} \quad$ Taku Fujimura $^{a} \quad$ Izuho Takeuchi ${ }^{b}$ Masatoshi Deguchi ${ }^{a}$ \\ Setsuya Aiba ${ }^{a}$ \\ ${ }^{a}$ Department of Dermatology, Tohoku University Graduate School of Medicine, Sendai, \\ and ${ }^{\mathrm{b}}$ Department of Dermatology, Kurihara Central Hospital, Kurihara, Japan
}

\section{Key Words}

Squamous cell carcinoma on the ear · Intra-arterial administration · Peplomycin · Superficial temporal artery

\begin{abstract}
Cutaneous squamous cell carcinoma (SCC) is the second most common non-melanoma skin cancer and tends to develop in sun-exposed cosmetic areas, including the ear. In this report, we describe two cases of SCC on the ear successfully treated with intra-arterial administration of peplomycin through a superficial temporal artery. In addition to this selective chemotherapy, we administered oral tegafur, which achieved complete remission of the tumor. These findings suggest that intra-arterial administration of peplomycin with tegafur is one of the optimal therapies for the treatment of SCC developing on the ear.
\end{abstract}

(c) 2014 S. Karger AG, Basel

\section{Introduction}

Cutaneous squamous cell carcinoma (SCC) is the second most common type of nonmelanoma skin cancer [1]. In general, the management of cutaneous SCC depends on its tumor stage. However, concerning high-risk patients or tumors on the cosmetic areas, the management of cutaneous SCC differs in each case $[1,2]$. Chemotherapy is one of the options 
Haga et al.: Successful Treatment of Two Cases of SCC on the Ear with Intra-Arterial Administration of Peplomycin through a Superficial Temporal Artery

for the treatment of inoperable cutaneous SCC. Though no standard treatment for cutaneous SCC has been formulated [2], the therapeutic effects of several anti-cancer drugs, including bleomycin, have been reported [3-5]. In this report, we describe two cases of SCC developing on the ear, for which complete remission was achieved with intra-arterial administration of peplomycin, a bleomycin derivative antibiotic, through a superficial temporal artery using an intravascular indwelling catheter.

\section{Case Reports}

Case 1

An 86-year-old Japanese man visited our outpatient clinic with a 4-month history of a red nodule on his ear. On his initial visit, physical examination revealed a red, dome-shaped, easy-to-bleed nodule with necrotic tissue on his right ear (fig. 1a). The size was approximately $100 \times 70 \mathrm{~mm}$ in diameter. A biopsy specimen revealed dermal infiltration of the tumor, which was composed of atypical keratinocytes with dyskeratotic cytoplasm (fig. 2a, b). The serum SCC antigen level (SCC Ag) was within normal range. We screened for a possible internal malignancy with a CT scan but found none, except for slight swelling of a cervical lymph node. From the above findings, we diagnosed this patient as poorly differentiated SCC, and for functional and cosmetic reasons, we selected intra-arterial administration of peplomycin through a superficial temporal artery using an intravascular indwelling catheter. We indwelled the point of the catheter at the feeding artery of the tumor by using indigo carmine (fig. 1b), and continuously administered $5 \mathrm{mg}$ of peplomycin per day intraarterially for 12 days. Four weeks after we finished the administration of peplomycin, the tumor mass had rapidly regressed, leaving a scar (fig. 1c). A biopsy specimen revealed that no tumor cells remained at this time point (fig. 2c, d). We added oral administration of $100 \mathrm{mg}$ tegafur for 8 weeks, and there has been no sign of local recurrence or systemic lesions for 18 months.

\section{Case 2}

A 70-year-old Japanese man visited our outpatient clinic with a 1-month history of a red nodule on his ear. On his initial visit, physical examination revealed a red, dome-shaped nodule with crust on his left ear (fig. 3a). The size was approximately $10 \times 10 \mathrm{~mm}$ in diameter. A biopsy specimen revealed dermal infiltration of the tumor, which was composed of atypical keratinocytes with dyskeratotic cytoplasm (fig. 4a). The serum SCC Ag was within normal range. We screened for possible internal malignancy with a CT scan but found none. From the above findings, we diagnosed this patient as well-differentiated SCC, and for functional and cosmetic reasons, we selected intra-arterial administration of peplomycin through a superficial temporal artery using an intravascular indwelling catheter. We continuously administered $5 \mathrm{mg}$ peplomycin per day intra-arterially for 9 days. Three weeks after we finished the administration of peplomycin, the tumor mass had rapidly regressed, leaving a scar (fig. 3b). A biopsy specimen revealed that no tumor cells remained at this time point (fig. $4 \mathrm{~b}, \mathrm{c}$ ). We added oral administration of $100 \mathrm{mg}$ tegafur for 2 months, and there has been no sign of local recurrence or systemic lesions for 12 months. 
Haga et al.: Successful Treatment of Two Cases of SCC on the Ear with Intra-Arterial Administration of Peplomycin through a Superficial Temporal Artery

\section{Discussion}

In this report, we describe two cases of SCC on the ear successfully treated with intraarterial administration of peplomycin through a superficial temporal artery. In addition to this selective chemotherapy, we administered oral tegafur, which achieved complete remission of the tumor. These findings suggest that the effect of intra-arterial administration of peplomycin with oral tegafur is one of the optimal therapies for the treatment of SCC developing on the ear.

Recently, Chitwood et al. [6] reviewed the efficacy of topical or intralesional treatment of non-melanoma skin cancer. Concerning SCC, the cure rate of imiquimod is $76 \%$ for SCC in situ (78/102) and 71\% for invasive SCC (5/7). The cure rate of topical 5-fluorouracil is $61 \%$ for SCC in situ (58/95). In contrast to topical administration of drugs, the cure rate of intralesional administration of interferon alpha-2 (IFN- $\alpha 2$ ) for SCC is $100 \%(3 / 3)$, that of IFN- $\alpha 2 b$ for SCC in situ is $89 \%$ (8/9) and that of IFN- $\alpha 2 b$ for invasive SCC $89 \%(25 / 28)$. These data suggest that the route for drug delivery is correlated with the clinical outcomes for the treatment of non-melanoma skin cancer.

Peplomycin is a bleomycin derivative antibiotic and its cytotoxicity toward mammalian cells is due to its ability to induce single- and double-strand DNA breaks by the induction of G1-phase specific apoptosis [7, 8]. For clinical application, peplomycin has recently been used as preoperative chemotherapy for SCC in Japan [3-5]. The total dose for conventional ways of peplomycin administration depends on its protocol (20-110 mg, bolus injection of $5-10 \mathrm{mg} /$ day) $[3,4]$. Though this reagent is useful for the treatment of SCC, especially in combination with radiation or other cytotoxic drugs, the dose for the administration of this reagent is limited because of its dose-dependent fatal side effects, such as interstitial pneumonia [3-5]. Therefore, an optimal method to keep a high concentration of peplomycin only in the tumor site is necessary. For the above reason, we selected intra-arterial, continuous administration of peplomycin through a superficial temporal artery for the treatment of cutaneous SCC on the ear. Indeed, in both of our two cases, the tumor mass decreased rapidly within 1 month. Moreover, skin biopsy after the administration of peplomycin revealed that no tumor cells remained. In addition, we administered oral tegafur, which is generally used as adjuvant chemotherapy or combination chemoradiotherapy for SCC in Japan $[9,10]$. Notably, a previous report also suggested that oral intake of tegafur after radical therapy significantly improves survival in cancer patients [10]. Therefore, in our present cases, we administered oral tegafur for the purpose of keeping the complete remission. Since the additional administration of oral tegafur might have prolonged the tumor-free time in our two cases, our present cases suggest the possibility of continuous intra-arterial administration of peplomycin through a superficial temporal artery using an intravascular indwelling catheter for the treatment of cutaneous SCC on the ear.

\section{Disclosure Statement}

The authors declare no conflict of interest. 
Haga et al.: Successful Treatment of Two Cases of SCC on the Ear with Intra-Arterial Administration of Peplomycin through a Superficial Temporal Artery

\section{References}

1 DeConti RC: Chemotherapy of squamous cell carcinoma of the skin. Semin Oncol 2012;39:145-149.

-2 Lansbury L, Bath-Hextall F, Perkins W, Stanton W, Leonardi-Bee J: Interventions for non-metastatic squamous cell carcinoma of the skin: systematic review and pooled analysis of observational studies. BMJ 2013;347:f6153.

3 Kirita T, Shimooka H, Yamanaka Y, Tatebayashi S, Yamamoto K, Nishimine M, Sugimura M: Prognostic value of response to preoperative chemoradiotherapy and residual tumor grades in tongue carcinoma. Oral Surg Oral Med Oral Pathol Oral Radiol Endod 2001;91:293-300.

-4 Isobe K, Uno T, Hanazawa T, Kawakami H, Yamamoto S, Suzuki H, Iida Y, Ueno N, Okamoto Y, Ito H: Preoperative chemotherapy and radiation therapy for squamous cell carcinoma of the maxillary sinus. Jpn J Clin Oncol 2005;35:633-638.

5 Sugiyama T, Hasuo Y, Nishida T, Kamura T: Impact on survival following successful neoadjuvant chemotherapy and radical surgery for stage IIb bulky and stage IIIb cervical cancer. Gynecol Oncol 2001;81:330-331.

6 Chitwood K, Etzkorn J, Cohen G: Topical and intralesional treatment of nonmelanoma skin cancer: efficacy and cost comparisons. Dermatol Surg 2013;39:1306-1316.

7 Okamura H, Morimoto H, Haneji T: Peplomycin-induced apoptosis in oral squamous cell carcinoma cells depends on bleomycin sensitivity. Oral Oncol 2001;37:379-385.

8 Chen HY, Zheng CY, Zou GL, Xie DX, Gong JP: Peplomycin induces G1-phase specific apoptosis in liver carcinoma cell line Bel-7402 involving G2-phase arrest. Acta Pharmacol Sin 2004;25:1698-1704.

-9 Shinoto M, Shioyama Y, Sasaki T, Nakamura K, Ohura H, Toh Y, Higaki Y, Yamaguchi T, Ohnishi K, Atsumi K, Hirata $\mathrm{H}$, Honda $\mathrm{H}$ : Clinical results of definitive chemoradiotherapy for patients with synchronous head and neck squamous cell carcinoma and esophageal cancer. Am J Clin Oncol 2011;34:362-366.

10 Hamada C, Tsuboi M, Ohta M, Fujimura S, Kodama K, Imaizumi M, Wada H: Effect of postoperative adjuvant chemotherapy with tegafur-uracil on survival in patients with stage IA non-small cell lung cancer: an exploratory analysis from a meta-analysis of six randomized controlled trials. J Thorac Oncol 2009;4: 1511-1516.
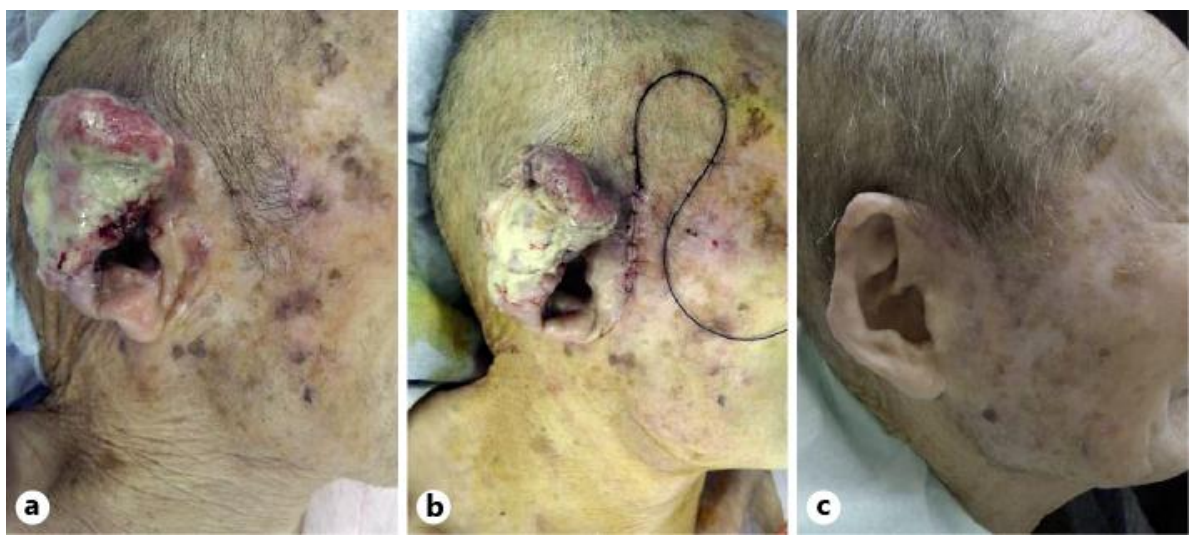

Fig. 1. a A red-colored, dome-shaped, $100 \times 70 \mathrm{~mm}$, easy-to-bleed nodule with necrotic tissue on the right ear. $\mathbf{b}$ We indwelled the point of the catheter at the feeding artery of the tumor by using indigo carmine. c Four weeks after the intra-arterial administration of peplomycin, the tumor had regressed, leaving a scar. 
Haga et al.: Successful Treatment of Two Cases of SCC on the Ear with Intra-Arterial Administration of Peplomycin through a Superficial Temporal Artery

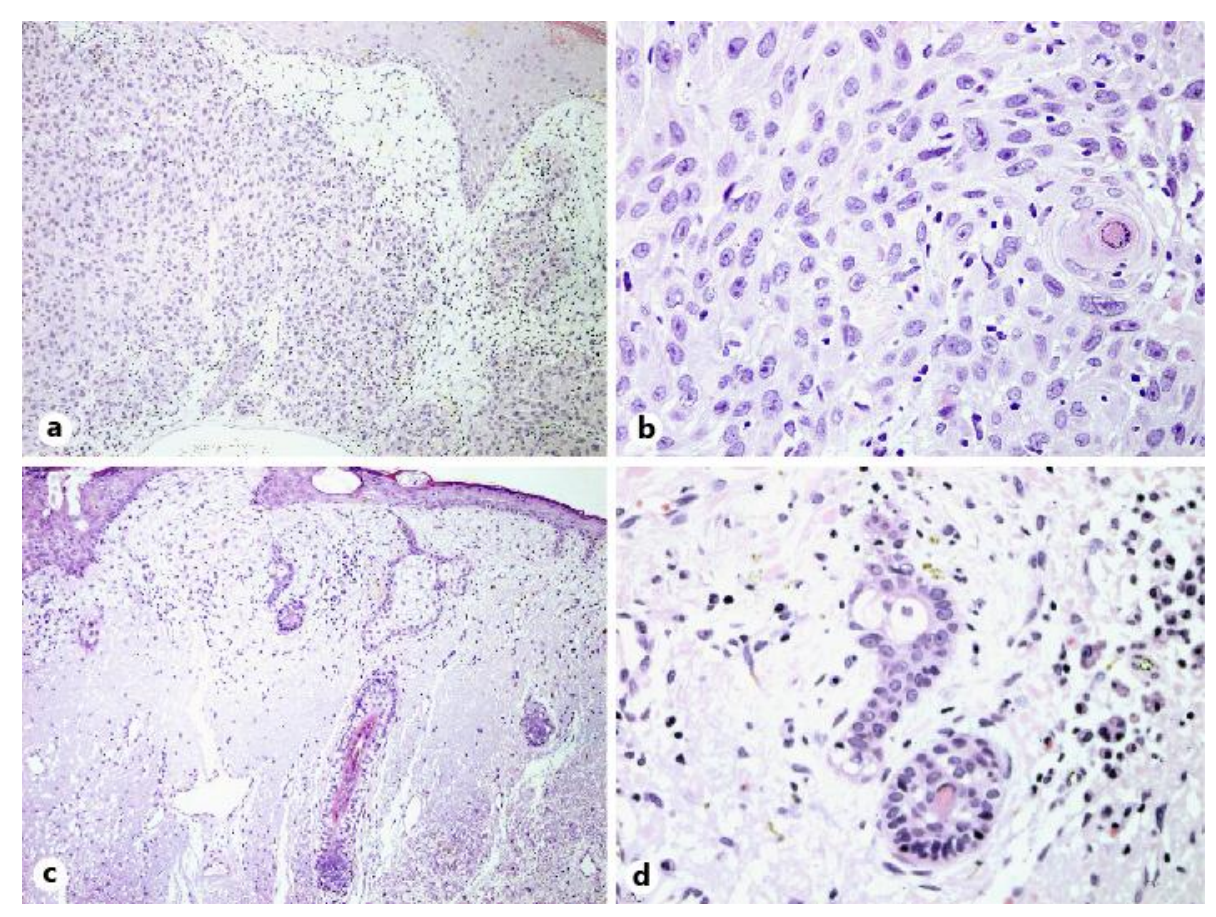

Fig. 2. a, b Dermal infiltration of the tumor, which was composed of atypical keratinocytes with dyskeratotic cytoplasm. c, d No tumor cells remained 4 weeks after the intra-arterial administration of peplomycin. Original magnification $\times 100(a, c)$ and $\times 400(b, d)$.
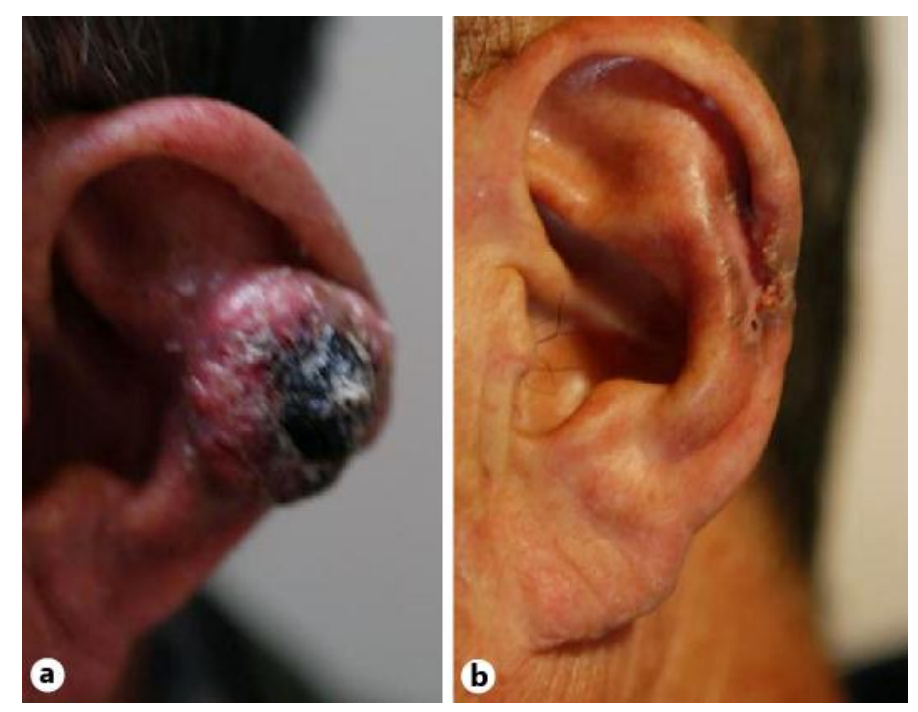

Fig. 3. a A red, dome-shaped nodule with crust on the left ear. b Three weeks after the intra-arterial administration of peplomycin, the tumor had regressed, leaving a scar. 
Haga et al.: Successful Treatment of Two Cases of SCC on the Ear with Intra-Arterial Administration of Peplomycin through a Superficial Temporal Artery

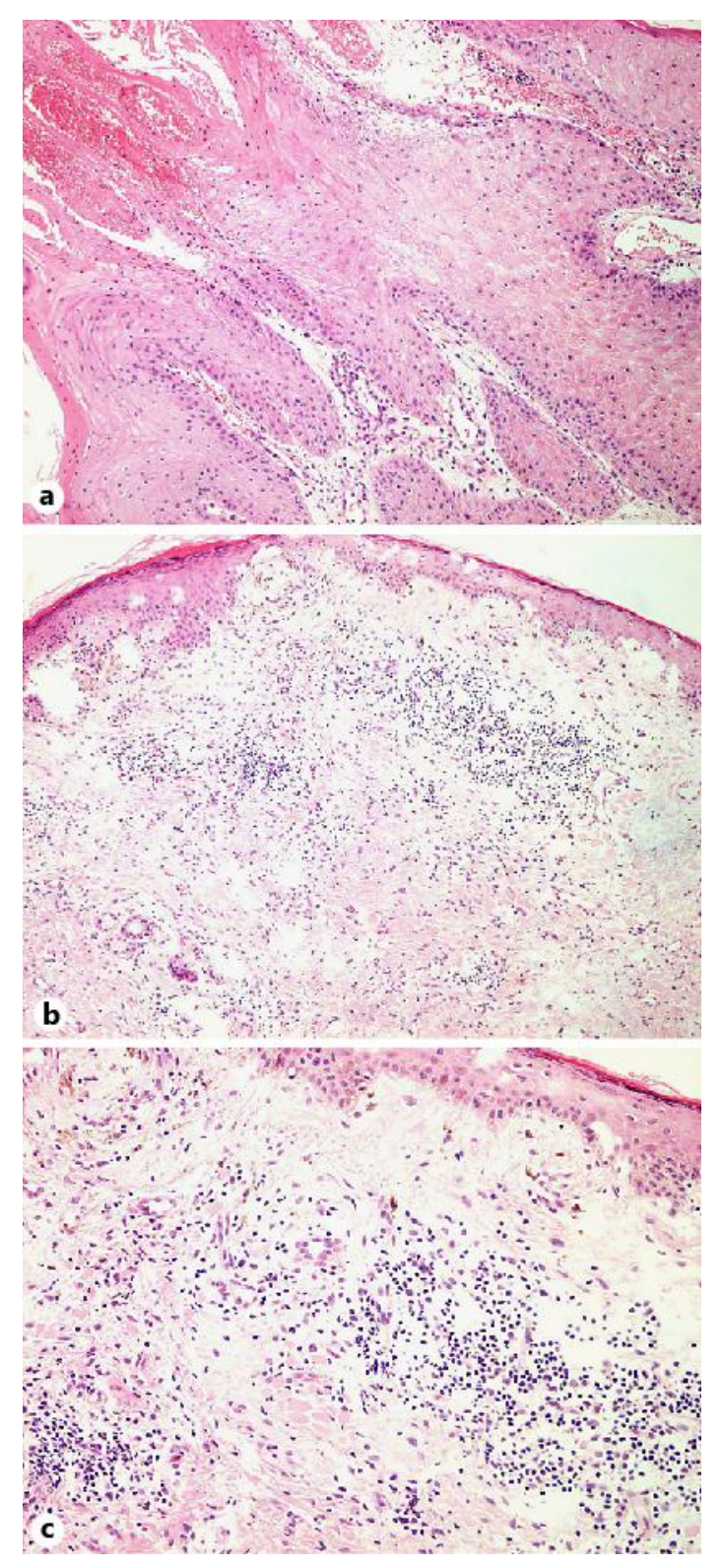

Fig. 4. a Dermal infiltration of the tumor, which was composed of atypical keratinocytes with dyskeratotic cytoplasm. b, c No tumor cells remained 3 weeks after the intra-arterial administration of peplomycin. Original magnification $\times 50(a, b)$ and $\times 200(c)$. 